\title{
Characterization and fat migration of palm kernel stearin as affected by addition of desiccated coconut used as base filling centre in dark chocolate
}

\begin{abstract}
The characterization and fat migration of palm kernel stearin (PKS) and desiccated coconut, used as base filling centre in dark chocolate were studied. C36 and C38 triglycerides of PKS decreased by $11 \%$ and $9.6 \%$ respectively, whereas C32 and C34 increased by $97 \%$ and $48 \%$ respectively. The change in the triglycerides composition of PKS shift the melting point of PKS from 33.2 to $31.4^{\circ} \mathrm{C}$. Solid fat content (SFC) of PK reduced by $40 \%$ at $30^{\circ} \mathrm{C}$. The rate of fat migration was very slow at $18^{\circ} \mathrm{C}$ storage compared to $30^{\circ} \mathrm{C}$. The rate of change of $\mathrm{C} 36$ in the chocolate layer was $0.1 \%$ week- 1 and $1.2 \%$ week- 1 at 18 and $30^{\circ} \mathrm{C}$ respectively. Chocolate stored at $18^{\circ} \mathrm{C}$ showed post hardening during storage period and withstood bloom during the storage period, whereas that stored at $30^{\circ} \mathrm{C}$ became soft and bloomed faster after 3 weeks of storage.
\end{abstract}

Keyword: Dark chocolate; Palm kernel stearin (PKS); Desiccated coconut; Fat migration 